\title{
Emerging Markets: Investing with Political Risk
}

\author{
Ephraim Clark \\ Middlesex University, U.K. \\ Radu Tunaru \\ Middlesex University, U.K.
}

This paper presents a model that measures the impact of political risk on portfolio investment when the political risks are multivariate and correlated across countries. The multivariate approach generalizes the single country model but retains most of its characteristics in terms of its ability to price political risk based on the stochastic process of exposure to loss and the expected frequency of loss causing events. The methodology is compatible with modern portfolio theory, straightforward to apply and can accommodate the traditional techniques in political risk assessment for the estimation of the relevant parameters (JEL D81, F23, G22, G31).

Keywords: geometric Brownian motion, insurance policy, Poisson arrival process, portfolio investment, political risk.

\section{Introduction}

The diversification benefits of portfolio investment in emerging markets has become a prominent feature of the financial globalization sweeping the world over the last decade. Besides market risk, however, investments in emerging markets are also exposed to political phenomena that are not generally present in the more developed economies. The Russian default, the Mexican peso crisis and the Asian economic meltdown are three of the more spectacular examples. This problem is well known to banks and multinational companies by the name of country or political risk and assessment techniques in these domains are relatively well developed. They are, however, generally

(Multinational Finance Journal, 2001, vol. 5, no. 3, pp. 155-173)

(C) Multinational Finance Society, a nonprofit corporation. All rights reserved.

DOI: $10.17578 / 5-3-1$ 
unadapted to portfolio investment in that they tend to ignore the diversification aspect associated with cross country correlations and are difficult to translate into practical decisions. ${ }^{1,2}$

Political risk for portfolio investment shares many of the characteristics of political risk for foreign direct investment (FDI). For example, portfolio investment values and cash flows are affected when political change causes unanticipated discontinuities in the business environment. This is the Robock and Simmonds (1973) definition of political risk. They are also affected by the risks pointed out by Root (1973) that include potential restrictions on the transfer of funds, products, technology and people, uncertainty about policies, regulations, governmental administrative procedures, and, finally, risks on control of capital such as discrimination against foreign firms, expropriation, forced local shareholding, etc. Wars, revolutions, social upheavals, strikes, economic growth, inflation and exchange rates all figure in the political risk literature and, obviously, are capable of affecting portfolio investment as well as direct investment.

Assessment techniques for political risk are as wide-ranging as the sources that generate it. Traditional methods for assessing political risk range from the comparative techniques of rating and mapping systems to the analytical techniques of special reports, dynamic segmentation, expert systems, and probability determination to the econometric techniques of model building and discriminant and logit analysis. These techniques are very useful for identifying and analysing individual sources of political risk but can handle neither cross relationships (correlations) nor accurate measurements of loss levels generated by the risks in question. For this reason it is difficult to translate the analysis into a practical decision making tool.

Traditional methods for incorporating political risk in the capital budgeting process are based on the work of Stonehill and Nathanson (1968) and Shapiro (1978) and Robock (1971). The first approach involves an ad hoc adjustment of the project's expected future cash flows to account for losses due to political risk while the second approach involves an ad hoc adjustment of the discount rate. Neither approach is consistent with the diversification principle of modern portfolio theory.

1. One exception is Clark (1991).

2. The problem of integrating political risk into foreign investment theory was discussed by Brewer (1991) and general issues related to the measurement of a firm's exposure to political risk were emphasized by Sethi and Luther (1986). 
More modern but less known methods for the evaluation of political risk and its incorporation in the capital budgeting process apply option pricing techniques that are consistent with modern portfolio theory and that can produce accurate measurements of the loss levels generated by the risks in question. ${ }^{3}$ Mahajan (1990) considers a single source of risk, expropriation, and measures its cost as the value of a European style call option held by the government on a non-dividend paying investment. Clark (1997 and 1998) extends Mahajan to consider various types of political risk, including expropriation. He uses an American style option framework that includes dividends and measures the cost of political risk as the value of an insurance policy that pays off all losses resulting from political events, which follow a Poisson process. Because the pricing mechanism is consistent with the diversification principle of modern portfolio theory, incorporating the political risk in the capital budgeting process involves estimating the project's NPV in the absence of political risk and then subtracting the cost of political risk reflected in the price of the option (Mahajan, [1990]) or the insurance policy (Clark, [1997] and [1998]). The same approach can be applied to portfolio investment.

This paper develops the theoretical framework for such an approach regarding the portfolio's exposure to political risk, which is conceptualised as an evolutionary process incorporating a continuous stochastic element and the discrete arrival of events that generate losses. It also proposes a major innovation. The foregoing "real option" approach assumes that individual political risks are uncorrelated with each other. Recent experience with "contagion" (for example, Mexico in 1994 and Asia in 1997) and the political fallout it engenders suggests that this assumption is unrealistic. Thus, this paper generalizes Clark (1997 and 1998) and considers (for the first time to our knowledge) the case of multiple sources of risk that are correlated across countries. This multivariate approach explicitly integrates the cross-country correlations in the estimation of the exposures to loss.

The rest of the paper is organised as follows. In section II we develop a general model for political risk in several countries where the risk is correlated across countries. Section III describes the mathematical properties of the model and proposes a solution for the

3. See Hull (2000, pp. 498-505) for a clear exposition of the theoretical framework linking systematic risk and the pricing of options. 
two country case. Section IV uses the two country solution to show how the model can be implemented in practice and to analyse the effect of the key parameters, country volatility and correlations on the cost of political risk. Section V summarizes the conclusions.

\section{Modelling Political Risk with Correlated Random Errors}

Let $x_{i}(t)$ be a geometric Brownian motion representing the exposure of a portfolio to loss in the case of an explicit political event in country $i$ measured in a common numeraire currency such as the US dollar. Taking a portfolio consisting of $n$ countries, the model is described by:

$$
d x_{i}(t)=\alpha_{2} x_{2}(t) d t+\sigma_{i} x_{2}(t) d z_{l}(t)
$$

where $i=1, \ldots, n$ and where $\alpha_{i}$ is the rate of growth of exposure to loss in country $i$; this depends on the rate of growth of the value of the investment determined by the investment's growth rate; $d z_{i}(t)$ is a Wiener process with zero mean and variance equal to $d t$; and $\sigma_{i}^{2}$ is the variance of $d x / x_{i}$. The Wiener processes are correlated with $E\left(d z_{i} d z_{j}\right)=$ $\rho_{i, j} d t$, and when $I=j, \rho_{i i}=1$.

The parameter $\sigma_{i}$ can be interpreted as the level of political risk in country $i$. It refers to ongoing change and measures the volatility of exposure to loss due to the ebbs and flows of the economic, social and political climate in the country. Volatility in the country's economic, social and political climate causes fluctuations in the amounts that can be lost if a loss causing political event actually occurs. The higher the volatility, the larger the fluctuations. The parameter $\rho_{i, j} d t$ captures the extent to which the economic, social and political climate in one country is correlated with the economic, social and political climate in another country.

A volatile economic, social and political climate does not in itself cause actual losses. For a loss to occur an explicit political event, such as legislation or decrees involving taxes, surcharges, tariffs or devaluation, strikes, boycotts, terrorist acts, etc., must take place. ${ }^{4}$ Suppose that loss causing political events occur at random times

4. The assumption here is that the level of political risk is constant. If this were not the case, losses could occur if something happened to increase the level of political risk. 
according to a Poisson arrival process with intensity parameter $\lambda_{i}$ and that each time a Poisson event occurs, there is a jump of magnitude equal to 1. Although Poisson events may occur more frequently in emerging markets, they are still rare events by definition with mean and standard deviation equal to the parameter $\lambda$. The arrival rates can vary from country to country, where a higher rate represents a higher risk. The risk environment is also captured in the geometric Brownian motion that models the amount at risk. Thus, if the potential loss is $x_{i}(t)$ when a Poisson event occurs in country $i$, the expected loss per time interval in country $i$ is then equal to $\lambda_{i} x_{i}(t) d t$. Therefore $\lambda_{i}$ can be called the current political risk probability parameter for country $i$.

Following Clark (1997), the tool proposed for measuring the cost of political risk is the value $V$ of a hypothetical insurance policy that pays off any and all losses up to the value of the investment arising from political events. Since stocks typically have no fixed maturity date, it is assumed that the insurance policy associated with the stocks has no fixed maturity date either and can be viewed as a perpetual claim. This means that $V$ does not depend directly on time and, therefore, is a function of only the exposures to political losses from the group of countries where the investments are made, $V=V\left(x_{1}(t), \ldots, x_{n}(t)\right)$.

The expected total return on the insurance policy is equal to the capital gain $E(d V)$ plus the expected cash flows:

$$
\sum_{i=1}^{n} \lambda_{i} x_{i}(t) d t
$$

generated by the explicit events in all countries over the time interval $d t$. With no loss of generality, assume risk neutrality and a constant risk free interest rate on the numeraire currency $r{ }^{5}$ Hence, the insurance policy will yield the riskless rate ${ }^{6}$ so that:

5. Risk neutrality holds in the risky world if we recognize that the drift parameter $a$ in the risk neutral world is equal to $\alpha^{*}-B\left(R_{m}-r\right)$, the risk adjusted growth rate minus the risk premium where $B\left(R_{m}-r\right)$ represents the CAPM's risk premium. See, for example, Hull (2000, pp 498-522) and Neftci (2000, pp 122-124 and 312-344). Relaxing the assumption of a constant riskless rate for a more realistic representation of the world economy is a promising avenue of research in the area.

6. The numeraire currency will usually be the base country of the investor. For the example described in section IV the investor is a US fund manager so the riskless rate is the one corresponding to the dollar. 


$$
\gamma V d t=E(d V)+\sum_{i=1}^{n} \lambda_{i} x_{i}(t) d t
$$

Applying a multivariate version of Ito's lemma, see Wilmott (1998), for $V=V\left(x_{1}(t), \ldots, x_{n}(t)\right)$ and taking expectations, gives the following partial differential equation:

$$
\frac{1}{2} \sum_{i=1}^{n} \sum_{j=1}^{n} \sigma_{i} \sigma_{j} \rho_{i j} x_{i} x_{j} \frac{\partial^{2} V}{\partial x_{i} \partial x_{j}}+\sum_{i=1}^{n} \frac{\partial V}{\partial x_{i}} \alpha_{i} x_{i}-\gamma V+\sum_{i=1}^{n} \lambda_{i} x_{i}=0 .
$$

\section{Mathematical Solution}

A general class of solutions to equation 3 is given by:

$$
V\left(x_{1}, \ldots, x_{n}\right)=\sum_{i=1}^{i-n} \frac{\lambda_{i} x_{i}}{\gamma-\alpha_{i}}+\sum_{1 \leq i<j \leq n} x_{i}^{m_{4}} x_{j}^{m_{f}}
$$

where the exponents in the second summation are determined from boundary conditions. One suitable set of boundary conditions (but not the only set) is based on the argument often applied in the insurance industry that the exposure to loss in any country can never be greater than the cost of the investment. If $S_{i}$ represents the cost of the investment in country $i$, this gives:

$$
\begin{gathered}
V\left(S_{1}, S_{2}, \ldots, S_{n-1}, x_{n}\right)=S_{1}+S_{2}+\ldots+S_{n-1}+\frac{\lambda_{n} x_{n}}{\gamma-\alpha_{n}} \\
V\left(S_{1}, S_{2}, \ldots, S_{n-2}, x_{n-1}, S_{n}\right)=S_{1}+S_{2}+\ldots+S_{n-2}+\frac{\lambda_{n-1} x_{n-1}}{r-\alpha_{n-1}}+S_{n}, \\
\cdots \\
V\left(x_{1}, S_{2}, \ldots, S_{n-1}, S_{n}\right)=\frac{\lambda_{1} x_{1}}{\gamma-\alpha_{1}}+S_{2}+\ldots+S_{n} .
\end{gathered}
$$

The particular solution to equation 3 for $n$ countries depends on its classification as parabolic, hyperbolic or elliptical, which must be determined from the discriminant matrix. For the purposes of tractability and comprehension, we solve for the particular case of only two countries and then use this solution for the example given in section 
IV. The mathematical solution, even for $n=2$, is quite complicated and there are many possibilities depending on the coefficients of the partial differential equation. This, however, does not weaken the practical pertinence of the model since numerical methods can easily provide a feasible solution for any number of countries greater than 2 at the expense of power computation.

This section contains a summary of the mathematical solutions for the case of $n=2$. The partial differential equation to be solved is then:

$$
\begin{gathered}
\sigma_{1}^{2} x_{1}^{2} \frac{\partial^{2} V}{\partial x_{1}^{2}}+2 \sigma_{1} \sigma_{2} x_{1} x_{2} \rho_{12} \frac{\partial^{2} V}{\partial x_{1} \partial x_{2}}+\sigma_{2}^{2} x_{2}^{2} \frac{\partial^{2} V}{\partial x_{2}^{2}} \\
+2 \alpha_{1} x_{1} \frac{\partial V}{\partial x_{1}}+2 \alpha_{2} x_{2} \frac{\partial V}{\partial x_{2}}-2 r V+\Lambda=0
\end{gathered}
$$

where the last term denotes the total losses given by the arrival of Poisson events, that is, $\Lambda=2 \lambda_{1} x_{1}+2 \lambda_{2} x_{2}$. This is a partial differential equation of second order and it has been the subject of intensive research in the literature, especially in mathematical physics. The mathematical techniques used for solving this equation and the final solutions depend on the relationships between the coefficients. A discussion of this equation is provided in textbooks such as O'Neil (1999). The domain of interest for our economic problem is:

$$
D=\left\{\left(x_{1}, x_{2}\right): x_{1}>0, x_{2}>0\right\}
$$

that is, only the first quadrant of the plane.

The first step is to calculate the discriminant of this equation, which is equal to:

$$
\Delta=\sigma_{1}^{2} \sigma_{2}^{2} x_{1}^{2} x_{1}^{2}\left(\rho_{12}^{2}-1\right)
$$

This simply means that the equation for the covering policy can be either parabolic, when $\rho_{12}= \pm 1$, that is when the Wiener processes are perfectly linearly correlated (positive or negative); or elliptic, when $\left|\rho_{12}\right|<1$. Since a perfect correlation between the error terms given by the Wiener processes is unlikely in practical applications, only the elliptic class of the partial differential equations is considered. Without reducing the generality of the problem, the calculus for the derivation 
of the solution can be simplified by assuming that $\sigma_{1}>\sigma_{2}$.

The general method of solving elliptic, second order partial differential equations is based on transforming the equation to a canonical form (O'Neil, [1999], pp 39). There are an infinite number of solutions and extra conditions are required in order to identify a unique solution. A second order ordinary differential equation has a unique solution when the value of the solution at a point and the value of its derivative at that point are specified. In a similar context with the one described here, this argument has been emphasized in Clark (1997). Since the equation is a second order partial differential equation, a similar methodology can be implemented to get a unique solution. The idea is to specify the values of the solution under some known extra conditions. A rationale for these extra conditions in the general case is provided by O'Neil (1999).

After a cumbersome sequence of transformations following the methodology described in Kevorkian (1990) and O'Neil (1999), it was possible to identify a class of solutions for the PDE (6). This class of analytical solutions (an infinite number) is given by:

$$
V\left(x_{1}, x_{2}\right)=x_{1}^{\psi-h} x_{2}^{w+h}+\frac{\lambda_{1}}{\left(r-\alpha_{1}\right)} x_{1}+\frac{\lambda_{2}}{\left(r-\alpha_{2}\right)} x_{2},
$$

where $w$ and $h$ have the formulae presented in appendix 2. The effects of country correlation represented by $\rho$ enter the solution via the exponents of the first term that makes the solution nonlinear. It is exactly this term that accounts for the difference in the quantitative solution from a simple additive solution of the cost of political risk for single countries.

The boundary conditions described below identify a single solution from the whole class of solutions that gives the exact cost of political risk for the entire portfolio.

\section{The boundary conditions}

In order to have a unique solution, the boundary conditions must be specified. For partial differential equations of second order it is not sufficient to give just the values in a fixed point of the solution's domain. The values of the solution along a given curve $\Gamma$, like any of the axes $V\left(x_{1}, 0\right)$, are usually given. However, this cannot be done for the problem at hand because of the restricted domain. 
From the many possibilities that are mathematically feasible, equation 5 defines a set of boundary conditions that are economically coherent and often applied in the insurance industry: the exposure to loss in any country can never be greater than the cost of the investment. Let $V^{\text {Clark }}(x)$ be the solution of the covering policy in only one country and $S_{1}$ and $S_{2}$ be the investment outlay for countries 1 and 2 respectively. The boundary conditions are then given as:

$$
V\left(S_{1}, x_{2}\right)=S_{1}+V^{\mathrm{c} \text { arth }}\left(x_{1}\right)
$$

and

$$
V\left(x_{1}, S_{1}\right)=S_{2}+V^{\text {clatk }}\left(x_{1}\right)
$$

for any $x_{1}>0, x_{2}>0$. The exit values act as absorbing barriers in the sense that once the risk exposure in one country reaches this value, it stays there forever and the value of coverage is equal to the cost of the investment. Consequently, the covering policy $V$ varies only in the other country and therefore, a unidimensional solution can be employed.

One last remark in this section. From the boundary conditions proposed above, in order to have economic sense, it follows that $r-\alpha_{1}-\lambda_{1}$ and $r-\alpha_{2}-\lambda_{2}$ should both be greater than zero. In addition, the feasible domain changes to:

$$
D=\left\{\left(x_{1}, x_{2}\right): 0<x_{1} \leq S_{1}, 0<x_{2} \leq S_{2}\right\}
$$

\section{Application and Analysis}

This section shows how to implement this tool in the portfolio risk analysis involving two countries and then analyzes the effects of the key parameters on the cost of political risk.

Consider the case of a US fund manager contemplating a \$200 million investment in Polish equities and a $\$ 300$ million investment in Hungarian equities. The riskless rate on the US dollar is $6.5 \%$ and the expected rate of capital appreciation on the Polish equities is $2 \%$ and on the Hungarian equities it is $1 \%$ so that $\alpha_{1}=0.02, \alpha_{2}=0.01$. Total dividend payments are forecasted as $\$ 35$ million per year for the Polish equities and $\$ 50$ million per year for the Hungarian equities. Based on historical data, loss causing events are expected to arrive at a rate of $\lambda_{1}=0.02$ for 
TABLE 1. Parameter Summary For Investment Analysis in Poland

\begin{tabular}{ccccc}
\hline$\alpha_{1}$ & $\sigma_{1}^{2}$ & $\lambda_{1}$ & $r$ & $x_{1}(0)$ \\
\hline .0200 & .0625 & .0200 & .0650 & $\$ 7.5$
\end{tabular}

TABLE 2. Parameter Summary For Investment Analysis in Hungary

\begin{tabular}{ccccc}
\hline$\alpha_{2}$ & $\sigma_{2}^{2}$ & $\lambda_{2}$ & $r$ & $x_{2}(0)$ \\
\hline .0100 & .5625 & .0400 & .0650 & $\$ 10$ \\
\hline
\end{tabular}

Poland and at a rate of $\lambda_{2}=0.04$ for Hungary. Suppose that the analysis shows that the level of political risk for Poland is equal to $\sigma_{1}^{2}=0.625$ and $\sigma_{2}^{2}=.5625$ for Hungary, and that in the immediate future, in the case of a political event, the investment would lose an average amount of $\$ 7.5$ million $\left(x_{1}(0)=\$ 7.5\right.$ million $)$ for Poland and $\$ 10$ million $\left(x_{2}(0)=\right.$ $\$ 10$ million) for Hungary. The information necessary for applying the model is summarized in tables 1 and 2.

With this information readily available, the next step is to calculate the measures for political risk for each country. To this end, a simple solution described in Clark (1998) is adopted:

$$
V^{c a x k}(x)=\frac{\lambda}{\gamma-a} x
$$

The resulting solutions will then be used as boundary conditions, thereby leading to a unique solution. The individual solutions are:

$$
V_{1}^{C s \pi k}=\frac{0.02}{0.065-0.02} \times 7.5 \cong 3.333 \text {, }
$$

and

$$
V_{2}^{C s w k}=\frac{0.05}{0.065-0.01} \times 10 \cong 7.27
$$

Using the information given in tables 1 and 2 and assuming for the moment that the correlation coefficient is $\rho_{12}=0.3$, the measure of 


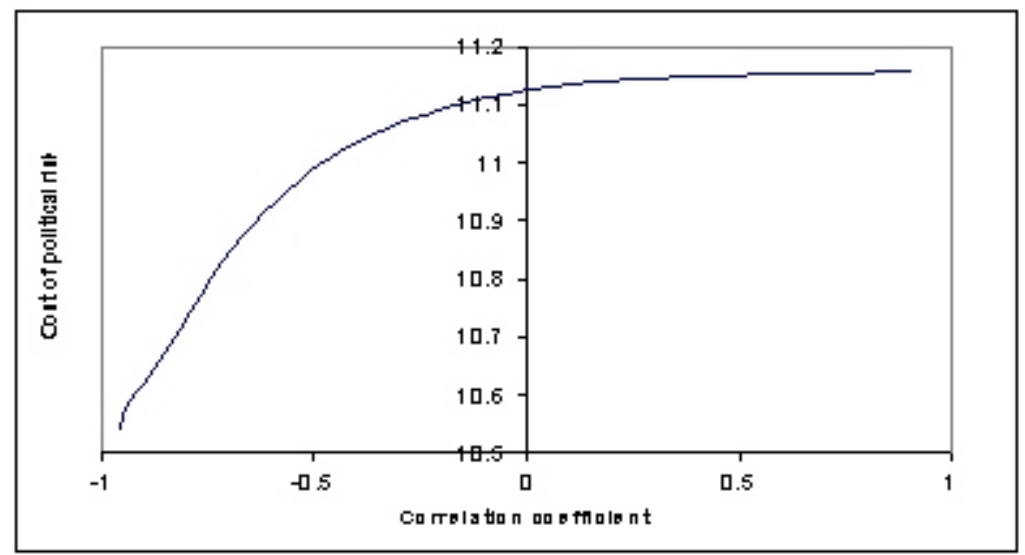

FIgURE 1.- Evolution of Cost of political risk $V$ when the correlation coefficient varies.

political risk covering both countries is calculated as:

$$
V\left(x_{1}, x_{2}\right)=x_{1}^{-0.21128} x_{2}^{-0.07353}+0.44 x_{1}+0.727 x_{2}
$$

Knowing that the current expected losses due to political events are $x_{1}(0)=\$ 7.5$ million for Poland and $x_{2}(0)=\$ 10$ million for Hungary, the cost of political risk is calculated as:

$$
\begin{gathered}
V(7.5,10)=7.5^{-0.11128} 10^{-0.07353}+0.44 \times 7.5+0.727 \times 10 \\
=11.14661+0.44 \times 7.5+0.727 \times 10=11.14661 .
\end{gathered}
$$

It is interesting to compare this value with the value obtained by summing the costs of political risk in each country as calculated by the Clark (1998) model: $\$ 3.33+\$ 7.27=\$ 10.6$. Thus, $V-\left(V_{1}+V_{2}\right)$ million dollars, showing that the political risk is underestimated by ignoring the correlation between the two countries. Hence, it appears that the correlations are pertinent for ascertaining the cost of political risk for a portfolio of assets.

To illustrate further the role of correlation on the cost of political risk, in figure 1 the correlation coefficient is allowed to vary from-0.99 to +0.99 (remember that the solution is for an elliptic PDE and does not 
hold for $\rho= \pm 1$ ). Notice that lower levels of $\rho$ are associated with lower levels of political risk. This result has intuitive appeal in that it corresponds to well established results in financial theory.

In figure 2 the same simulation as in figure 1 is performed with different values of volatility. In figure $2 \mathrm{a}$ both volatilities increase by $20 \%$, in $2 \mathrm{~b}$ both decrease by $20 \%$, and in $2 \mathrm{c}$ one increases by $20 \%$ and the other decreases by $20 \%$. What shows up in this simulation is that the correlation coefficient still has the same powerful effect on the cost of political risk but that the effect of the individual volatilities is relatively small. Although the effect of volatility on political risk is in the right direction - increases increase the cost and decreases decrease it - a 20\% change in volatility has less than a $5 \%$ effect on the value of the insurance policy.

In figure 3 the simulation is performed with different values for the drift parameters. In $3 \mathrm{a}$ both drift parameters are increased by $20 \%$; in $3 \mathrm{~b}$ both are decreased by $20 \%$ and in $3 \mathrm{c}$ one increases by $20 \%$ and the other decreases by $20 \%$. Here the correlation effect is undiminished. The drift effect is in the expected direction - higher drift parameters increase the cost of political risk and lower drift parameters decrease it. However, the drift effect, although more pronounced than the volatility effect, still seems relatively weak in that a $20 \%$ variation in the parameters causes a variation of less than $20 \%$ in the insurance policy.

Figure 4 continues with the same simulation but with different values for the riskless rate. In $4 \mathrm{a}$ the riskless rate increases by $20 \%$ and in $4 \mathrm{~b}$ it decreases by $20 \%$. Again the correlation effect is undiminished but here the effect of the riskless rate is substantial. A 20\% change causes a change of more than $20 \%$ in the value of the insurance policy.

All three graphs show the same pattern, a concave increasing curve starting from a lower value corresponding to a correlation coefficient close to -1 to a higher value corresponding to a correlation coefficient close to 1 (recall that the solution is not valid for the case when the correlation coefficient is equal to -1 or 1 ). The value of the policy is relatively insensitive to changes in the volatilities and the drift parameters while it is very sensitive to changes in the interest rate. The role of each of these parameters is similar for $n>2$ countries, based on simulations with 3 and 4 countries using numerical solution methods.

Since the cost of political risk is in a sense a premium over the risk free interest rate $r$, everything else being equal, the cost of political risk should be higher if the same chain of events occurs in situations where the risk free interest rate is smaller. This conjecture is confirmed in 

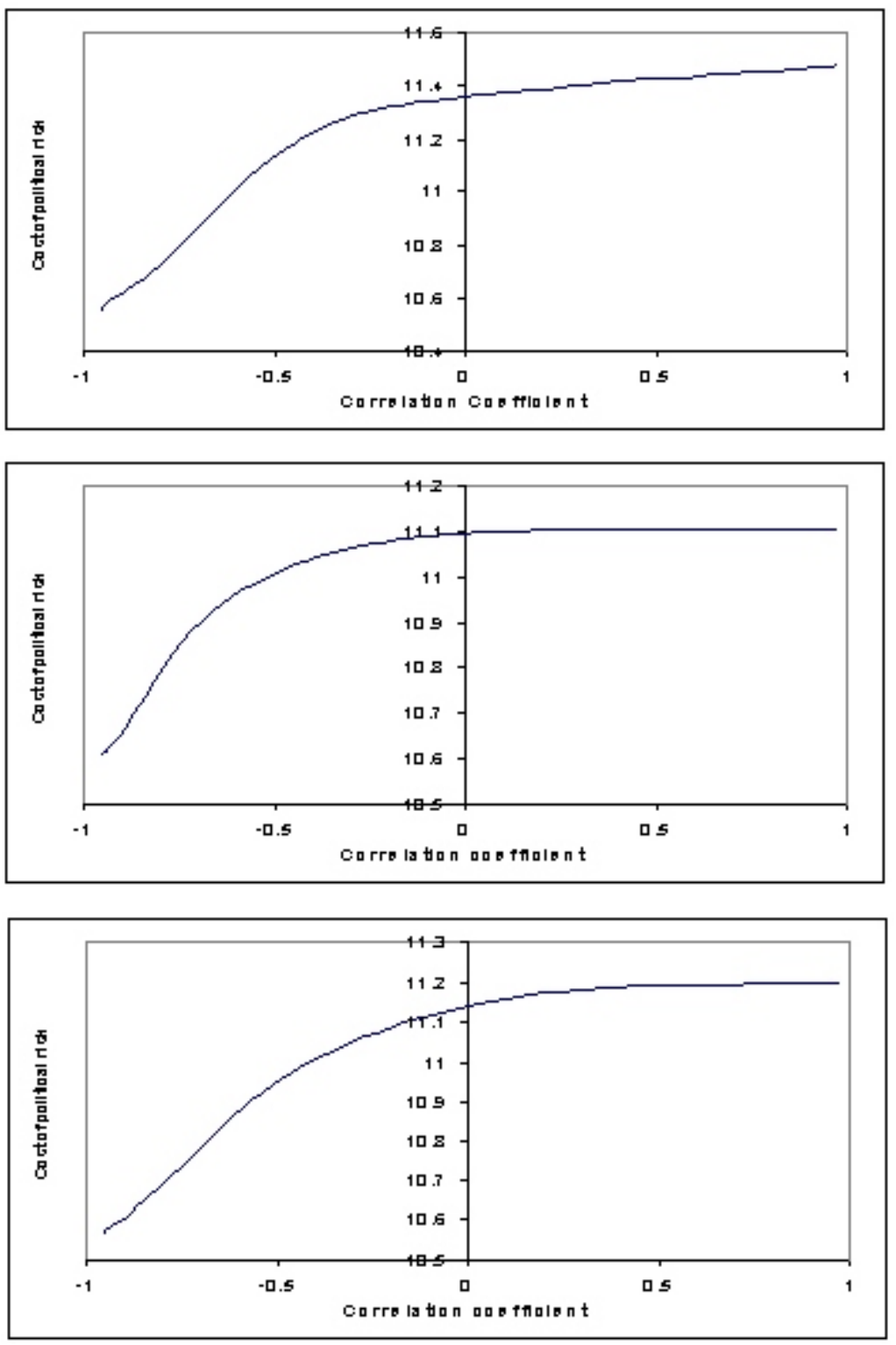

FIGURE 2.- Cost of political risk $V$ when the volatility parameters are changed by $20 \%$ up and down. a) $\sigma_{1}=0.3$ and $\sigma_{2}=0.9$, b) $\sigma_{1}=0.2$ and $\sigma_{2}=0.6$, and c) $\sigma_{1}=0.3$ and $\sigma_{2}=0.6$. 

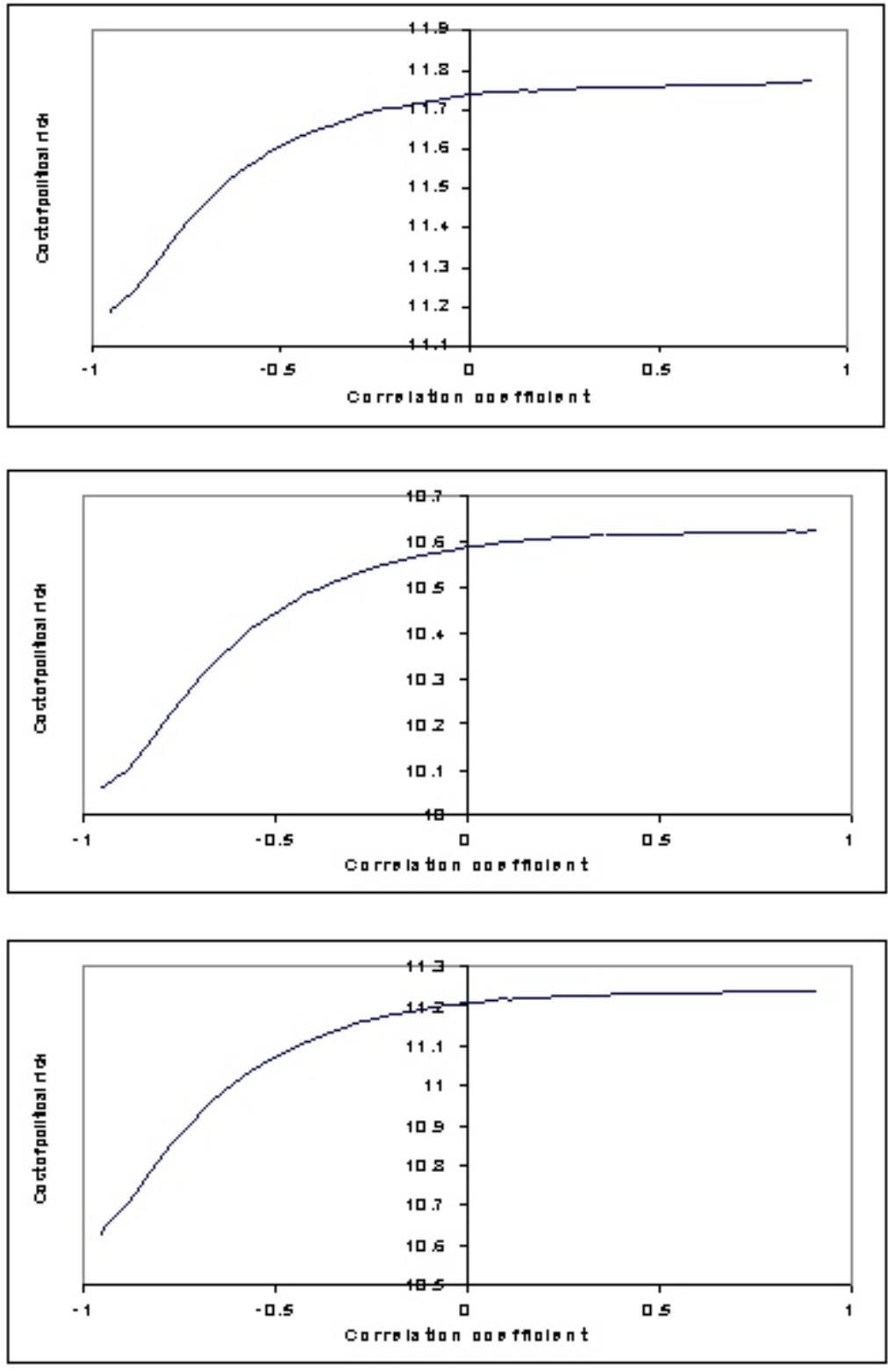

Figure 3.-Cost of political risk $V$ when the drift diffusion parameters are changed by $20 \%$ up and down. a) $\alpha_{1}=0.024$ and $\alpha_{2}=0.012$, b) $\alpha_{1}$ $=0.016$ and $\alpha_{2}=0.008$, and c) $\alpha_{1}=0.024$ and $\alpha_{2}=0.008$. 

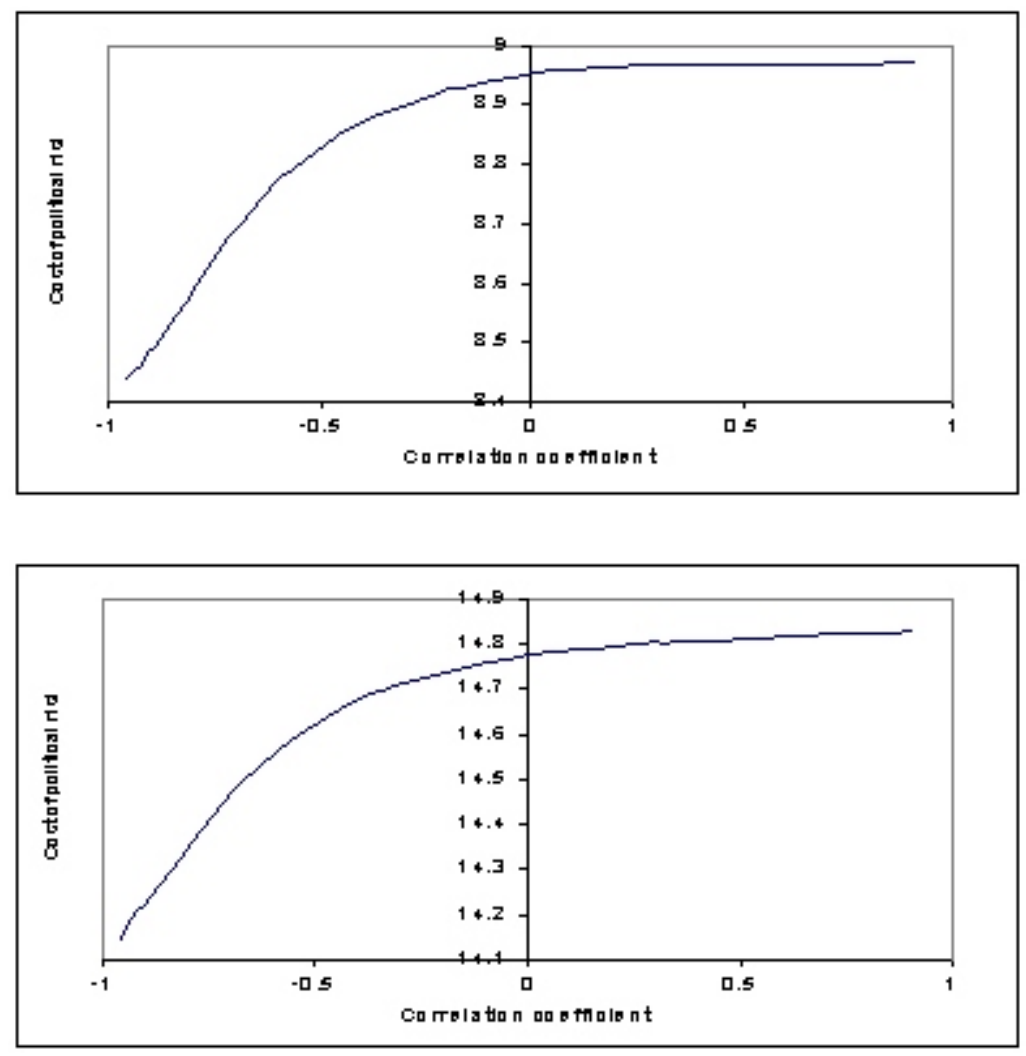

FIGURE 4.- Cost of political risk $V$ when the riskless rate parameter is changed by $20 \%$ up and down. a) $r=0.078$, b) $r=0.052$.

figure 5 which is a three-dimensional plot of the cost of political risk when both correlation coefficient and risk free interest rate are varying. When $r$ goes larger and larger, up to $60 \%$ in figure 5 , the cost of political risk stabilizes to a constant low platform as expected.

One may conjecture that dramatic increases in volatility associated with high correlations between the countries should increase the insurance policy drastically. Using the example discussed at the beginning of this section with the corresponding parameters, figure 6 explores this scenario on a three-dimensional graph with the second volatility parameter varying up to $205 \%$. It is confirmed that the cost of political risk increases with volatility and the correlation between the two countries. 


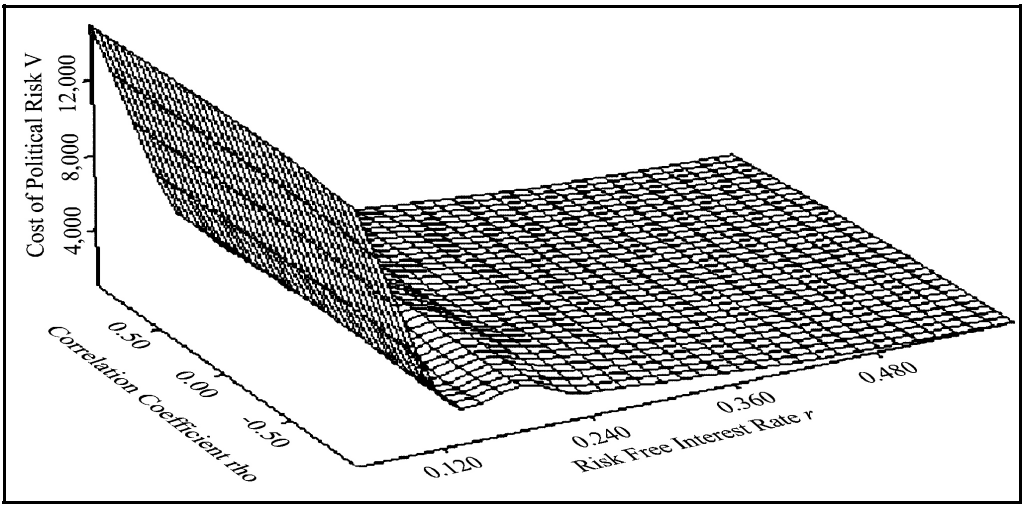

Figure 5.-Cost of political risk $V$ when the risk free interest rate $r$ varies between $5 \%$ and $60 \%$ and the correlation coefficient rho varies between -1 and 1 .

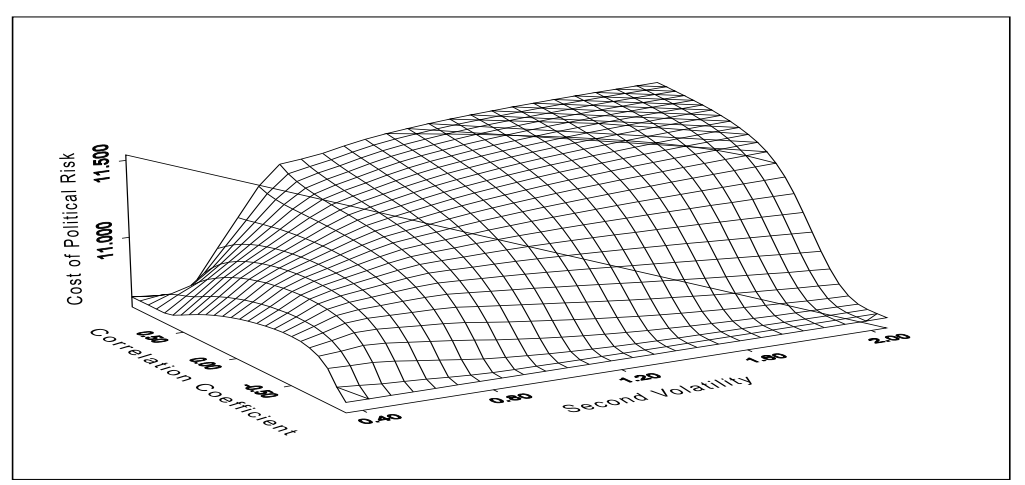

FiguRE 6.-Evolution of cost of political risk when the correlation coefficient varies and the second volatility parameter varies from $35 \%$ to $205 \%$.

\section{Conclusion}

Although there is an abundant literature on political risk in emerging markets, the relevant assessment techniques are generally not well adapted to portfolio investment because they ignore the diversification aspect associated with cross-country correlations and are difficult to 
translate into practical decisions. This paper developed a framework for overcoming these problems and extended the methodology proposed in Clark (1997 and 1998) to international portfolio investment. Using economic intuition to determine the boundary conditions, it also showed how to derive an analytical solution for the case of two countries. The same kind of economic intuition can be used along with numerical methods to derive solutions for any number of countries. Finally, in the simulation of the two-country case, it showed how the methodology can be applied in practice to estimate the political risk of an international investment portfolio and that cross-country correlations have a crucial impact on its actual riskiness.

The methodology is tractable and compatible with modern portfolio theory. It is also relatively straightforward to apply in practice. A major feature of the methodology is that it can accommodate the traditional techniques in political risk assessment for the estimation of the relevant parameters. Thus, as a complementary tool, it enhances their value and makes it possible for them to be effectively applied in the domain of portfolio investment.

Further research involves a case study of a portfolio consisting of a large number of countries and the development of tools for testing the methodology using an endogenous Bayesian updating process.

\section{Appendix 1 - The Derivation of Equation}

Using a multivariate version of Ito lemma, see Wilmott (1998), gives:

$$
d V=\left(\frac{\partial V}{\partial t}+\frac{1}{2} \sum_{i=1}^{n} \sum_{j=1}^{n} \sigma_{i} \sigma_{j} \rho_{i j} x_{i} x_{j} \frac{\partial^{2} V}{\partial x_{1} \partial x_{j}}\right) d t+\sum_{i=1}^{n} \frac{\partial V}{\partial x_{i}} d x_{i} .
$$

Recalling that $V$ does not depend on time and replacing $d x_{i}$ gives:

$$
d V=\frac{1}{2} \sum_{i=1}^{n} \sum_{j=1}^{n} \sigma_{i} \sigma_{j} \rho_{i j} x_{i} x_{j} \frac{\partial^{2} V}{\partial x_{i} \partial x_{j}} d t+\sum_{i=1}^{n} \frac{\partial V}{\partial x_{i}}\left[\alpha_{i} x_{i} d t+\sigma_{i} x_{i} \alpha z_{i}(t)\right] .
$$

Taking the expectation and using the properties of Wiener processes, gives

$$
E(d V)=\frac{1}{2} \sum_{i=1}^{n} \sum_{j=1}^{n} \sigma_{i} \sigma_{j} \rho_{i j} x_{i} x_{j} \frac{\partial^{2} V}{\partial x_{i} \partial x_{j}} d t+\sum_{i=1}^{n} \frac{\partial V}{\partial x_{i}} \alpha_{i} x_{i} d t,
$$

and therefore equation 2 becomes: 


$$
\gamma V=\frac{1}{2} \sum_{i=1}^{n} \sum_{j=1}^{n} \sigma_{i} \sigma_{j} \rho_{i} x_{i} x_{j} \frac{\partial^{2} V}{\partial x_{i} \partial x_{j}}+\sum_{i=1}^{n}\left(\frac{\partial V}{\partial x_{i}} \alpha_{i} x_{i}+\lambda_{i} x_{i}\right)
$$

\section{Appendix 2 - The formulae for $w$ and $h$}

This appendix contains the formulae for the power coefficients involved in the solution given in equation 6 in the main body of the paper. They are:

$$
w=\frac{2 b \sigma_{1} a_{12} \sqrt{1-a_{12}^{2}}+\alpha\left[\sigma_{1}^{2}+\sigma_{1}-\sigma_{1} a_{12}^{2}\left(1-\sigma_{1}\right)\right]}{\left(\sigma_{1} a_{12}-\sigma_{2}\right) \sqrt{1-a_{12}^{2}}}
$$

and

$$
h=2 b-\alpha \frac{\sigma_{1}^{2}-\sigma_{1}^{2}-2 \sigma_{1} \sigma_{2} a_{12}+2 \sigma_{1}^{2} a_{12}^{2}}{\left(\sigma_{1} a_{12}-\sigma_{2}\right) \sqrt{1-\rho_{12}^{2}}}
$$

with $a$ and $b$ any real numbers such that

$$
a^{2}+b^{2}+s_{1} \alpha+s_{2} b-s_{3}=0
$$

where

$$
\begin{aligned}
& s_{1}=\frac{\sigma_{2}-\sigma_{1} \rho_{12}}{2 \sigma_{1} \sigma_{2}^{2} \sqrt{1-\rho_{12}^{2}}} \times\left[\frac{\left(2 \alpha_{1}+\sigma_{1} \rho_{12}\right) \sigma_{1}^{3}-2 \sigma_{1} \sigma_{1} \rho_{12}\left(\alpha_{1}+\alpha_{1}\right)}{\sigma_{2}^{2}-2 \sigma_{1} \sigma_{2} \beta_{12}+4 \sigma_{1}^{2}-3 \sigma_{1}^{2} \rho_{12}^{2}}\right. \\
& \left.-\frac{\sigma_{1}^{2} \sigma_{2}^{2} \beta_{12}\left(1+\beta_{12}\right)+2 \alpha_{1} \sigma_{1}^{2} \rho_{12}\left(1+\beta_{12}\right)}{\sigma_{2}^{2}-2 \sigma_{1} \sigma_{2} \rho_{12}+4 \sigma_{1}^{2}-3 \sigma_{1}^{2} a_{12}^{2}}\right] \\
& +\frac{\sigma_{1}-\sigma_{1} \rho_{12}}{2 \sigma_{1} \sigma_{1}^{2} \sqrt{1-\rho_{12}^{2}}} \times \frac{\sigma_{1}^{3} \sigma_{2} \rho_{12}-2 \alpha_{1} \sigma_{1}^{2}}{\sigma_{1}^{2}-2 \sigma_{1} \sigma_{2} \rho_{12}+4 \sigma_{1}^{2}-3 \sigma_{1}^{2} \rho_{12}^{2}} \\
& s_{2}=\frac{\left(\sigma_{2}-\sigma_{1} \beta_{12}\right)\left[2\left(\alpha_{1}+\alpha_{2}\right) \sigma_{2}+2 \sigma_{1} \sigma_{2}^{2} \beta_{12}-4 \alpha_{1} \sigma_{1} \beta_{12}-\sigma_{2} \sigma_{1}^{2}-\sigma_{2}^{3}\right.}{2 \sigma_{2}^{2}\left[2 \sigma_{2}^{2}-2 \sigma_{2} \sigma_{1} \beta_{12}+\left(\sigma_{1}^{2}-\sigma_{2}^{2}\right) \beta_{12}^{2}\right.} \\
& s_{3}=\frac{r\left(\sigma_{2}-\sigma_{1} \beta_{12}\right)^{2}}{4 \sigma_{2}^{2}\left(\sigma_{2}^{2}-2 \sigma_{2} \sigma_{1} \beta_{12}+\sigma_{1}^{2}\right.} .
\end{aligned}
$$

Condition $3 \mathrm{~B}$ can be used to check whether the calculations are correct. For the simulated example described above, the condition 3B is indeed verified. 


\section{References}

Brewer, T.L. 1991. Integrating political variables into foreign investment theory: An analytical framework. Paper presented at the 1991 AIB meeting in Miami.

Clark, E. 1991. Cross bord er investment risk. London: Eurom oney Publications.

Clark, E. 1997. Valuing political risk. Journal of International Money and Finance 16: 477-490.

Clark, E. 1998. Political risk in Hong Kong and Taiwan: Pricing the China factor, Journal of Economic Integration 13 (2): 276-291.

Hull, J.C. 1999. Options, futures, \& other derivatives. 4th edition, London: Prentice Hall International.

Kevorkian, J. 1990. Partial differential equations. Analytical solution Techniques. New York: Chapman \& Hall.

Mahajan, A. 1990. Pricing expropriation risk, Financial Management (Winter): 77-86.

O’Neil, P.V. 1999. Beginning partial differential equations. New York: John Wiley \& Sons.

Robock, S. H. and Simmonds, K. 1973. International business and multinational enterprise. Homewood: R. Irwin.

Root, F. 1973. Analysing political risks in international business. In A. Kapoor and Ph. D. Grub (eds). Multinational Enterprise in Transition. Princeton: Darwin Press.

Sethi, P.S., and Luther, K.N. 1986. Political risk analyses and direct foreign investment: Some problems of definition and measurement, California Management Review 28: 57-68.

Shapiro, A. C. 1978. Capital budgeting for the multinational corporation, Financial Management 7 (Spring): 7-16.

Stonehill, A., and Nathanson, L. 1968. Capital budgeting and the multinational corporation, California Management Review 4 (Summer): 39-54.

Wilmott, P. 1998. Derivatives: The theory and practice of financial engineering. London: John Wiley \& Sons. 